\title{
Analyzing Low Impact Development Strategies Using Continuous Fully Distributed Coupled Groundwater and Surface Water Models
}

\author{
Mason M. Marchildon and J. D. C. (Dirk) Kassenaar
}

Low impact development (LID) strategies have received attention in recent years as offering a potential way to mitigate the adverse effects of urbanization on hydrologic flow and water quality. The obvious benefits of reduced peak flows and the sizing of storm water ponds can be simulated in models such as USEPA's SWMM; however, the analysis of LID system interaction with the groundwater system is challenging.

Addressing questions related to local infiltration capacity, feedback from the groundwater system (i.e. rejected recharge and saturation-excess runoff), and ecological benefits, including the preservation of baseflow and wetland hydroperiod, requires a spatially distributed and integrated analysis of the hydrologic system. The purpose of this chapter is to illustrate the challenges and insights that the authors have encountered while simulating and comparing the effectiveness and ecological benefits of different LID scenarios using an integrated groundwater and surface water model.

Additional discussion addresses how this approach can be used to complement storm water modeling and provide for a complete analysis of LID functionality.

Marchildon, M. and D. Kassenaar. 2013. "Analyzing Low Impact Development Strategies Using Continuous Fully Distributed Coupled Groundwater and Surface Water Models." Journal of Water Management Modeling R246-17. doi: 10.14796/JWMM.R246-17.

(C) CHI 2013 www.chijournal.org ISSN: 2292-6062 (Formerly in Pragmatic Modeling of Urban Water Systems. ISBN: 978-0-9808853-8-5) 


\subsection{Introduction}

In recent years, there has been growing concern over the impact of urban development on existing hydrological systems. The concern varies from water quality to water quantity; and from peak flow events that impose erosional hazards on urban infrastructure and channel stability to the low flow regime that consequently affects wetland hydroperiod and baseflow discharge. In order to mitigate the impacts of urbanization, low impact development (LID) strategies have been suggested by various agencies (e.g. Credit Valley Conservation and Toronto and Region Conservation Authority, 2010). These strategies include various forms of retention and detention mechanisms that can increase evaporative loss, increase local infiltration, reduce peak flow discharge, attenuate overland flow, and maintain acceptable water quality.

From a modeling perspective, new algorithms to evaluate LID strategies have recently been added to hydraulic models commonly used for storm water management (e.g. SWMM5). These models evaluate end-of-pipe peak flow and water quality changes related to the LID options being considered. While these models simulate many of the benefits of the LID options, they do not address what happens to the locally captured water, so they cannot answer important issues concerning a LID implementation, such as: Will the designed LID functionality be possible given the local conditions? If so, will LID plans actually preserve or restore the ecological function of the local and regional setting?

For example, analysis of LID functionality involving enhanced infiltration is required when the objective is to mitigate ecological deterioration in streams and wetlands caused by reduced groundwater recharge. A lumped parameter hydrologic catchment model cannot identify the optimum type and placement of infiltration enhancement LID strategies because that requires the consideration of local terrain, proximity to existing natural heritage features, soil and subsurface geology, and depth to water table. These details need to be assessed using a distributed coupled surface and subsurface model that can consider both the local function and regional eco-hydrological benefit of the LID strategy.

This chapter demonstrates how an integrated groundwater and surface water model was coupled with a stormwater management model to address all aspects of LID implementation. Examples presented in this chapter show how an existing multi-aquifer groundwater model was upgraded in order to complete the LID assessment. Comparisons between the simulated pre- and post-development conditions were used to quantify the direct impacts of urbanization on groundwater levels, groundwater discharge to streams (at the reach scale), aquatic systems and habitat. 


\subsection{GSFLOW Model Description}

\subsubsection{Overview}

The first step in the integrated assessment of a LID strategy is the selection of an appropriate model for use in conjunction with the storm water modeling analysis. The requirements of this model include the ability to simulate hydrologic processes, infiltration partitioning and groundwater flow, plus the capability to represent LID strategies within that framework. The authors have selected and applied the U.S. Geologic Survey (USGS) GSFLOW model because of its spatial flexibility and the availability of model source code that could be modified to represent of a variety of LID options.

The groundwater-surface water flow (GSFLOW) model is a fully integrated distributed hydrologic model developed by the USGS, first released in June 2008. The documentation (Markstrom et. al., 2008) and source code are freely available at the USGS website. GSFLOW represents the integration of the precipitation-runoff modeling system (PRMS; Leavesley, 1983) hydrology model and the widely used modular groundwater flow model (MODFLOW; Harbaugh, 2005). The model conceptualization generally conforms to the integrated model design proposed by Freeze and Harlan (1969).

The following is a description of the model design and simulation processes. We refer the reader to Markstrom et al. (2008) and the references therein for further technical details. The model process overview is followed by a description of the incorporation of the LID simulation options into GSFLOW.

\subsubsection{Spatial and Temporal Discretization}

The ability to represent the specific geometric details of a proposed LID design is central to answering the questions about LID function and effectiveness at both a local and cumulative scale. The groundwater system is represented in GSFLOW by subdividing the domain into layers of rectangular cells, each with unique properties. Cell size can vary throughout the model space to better represent local conditions and LID details. Lakes and wetlands represented as lake cells can penetrate multiple model layers so as to fully represent groundwater-lake interactions. Streams are represented as a network of channels that receive inputs from overland flow processes while maintaining a direct connection to the groundwater system. The hydrologic processes, including climate, surface runoff and soil zone processes, are also represented as a fully distributed grid of cells, each with unique physical properties.

GSFLOW is unique in that the surface water and overland runoff processes can be simulated on a different distributed grid resolution than the 
groundwater system. This is particularly advantageous as surface information and design details (e.g. digital elevation models, soil mapping and land use planning) are often far more detailed than subsurface geologic information. The ability to independently refine surface and subsurface components of the distributed model, and simulate the processes and LID capabilities in a computationally efficient integrated manner, is essential for design scenario analysis and comparison.

The temporal resolution of the simulations is also significant. Select processes can be simulated on a variable time step, but the fundamental coupling of the surface water and groundwater processes is completed on a daily time step. This coupling time step is appropriate for the groundwater and ecohydrological focus of the GSFLOW LID analysis.

\subsubsection{Hydrology: Climate, Overland Flow and Soil Zone}

The distributed nature of GSFLOW allows for the application of distributed meteorological data such as radar based precipitation. Slope and aspect are calculated from the cell based digital elevation model (DEM) to correct for solar irradiation effects on snow melt and evapotranspiration losses. DEM elevations can be used to apply lapse rates and provide elevation-corrected temperatures where necessary.

Potential evapotranspiration (PET) is computed using pan evaporation data or the Jensen-Haise formulation (Jensen et al., 1969), which incorporates solar radiation and mean daily temperatures. Actual evapo-transpiration (AET) is limited by PET and available water is stored in the interception, depression and soil zone stores. After the surface water stores are depleted and there remains some available PET, evapotranspiration will occur from both the unsaturated and saturated groundwater zones (if the user defined depth from surface to these zones permits evaporative losses).

Interception, pervious depression and impervious depression stores are handled independently using the same mechanism: storages are given a maximum capacity based on storage depth and storage coverage; these stores are filled and depleted first from precipitation and evaporation, respectively, before the model begins to account for other processes such as net precipitation (i.e. throughfall) onto and evapotranspiration from the soil zone.

Snowmelt is calculated using a 1-D energy-balance equation that accounts for energy gains and losses through various mechanisms such as incoming shortwave radiation, incoming and outgoing longwave radiation, latent and sensible heat exchanges, energy added from rainfall onto the snowpack, and loss of latent heat of fusion due to melt water leaving the snowpack. 
Energy losses and gains conducted through the ground beneath the snowpack are assumed to be negligible. The snowpack is represented as having two layers: a surface layer which is exposed to solar radiation and accounts for a variable surface albedo, and a lower layer that generally contains most of the snowpack mass. GSFLOW updates the net energy store of the snowpack twice daily, for the daytime and evening. The snowpack is treated as a porous medium, allowing for mass redistribution and a liquid water content that can re-freeze if possible. The 1-D energy balance model is then coupled with a 2-D areal depletion curve to account for snow accumulation along fence lines or roadside ditches. Areal depletion curves can also be applied on a cell by cell basis.

Many options of infiltration excess (i.e. Hortonian) runoff generation are available in GSFLOW: a linear and a nonlinear variable source area concept (Dickinson and Whiteley, 1970), the Soil Conservation Service curve number (CN) methodology (USDS SCS, 1985), and a Green-Ampt (1911) infiltration model for sub-daily time steps. Infiltration is then added to the soil zone that has been conceptualized as having three soil zone stores: capillary (i.e. tension) storage, gravity storage and preferential flow storage. Capillary storage is conceptualized as the portion of the soil moisture capacity where water is kept under tension and thus is unaffected by gravitational forces (i.e. field capacity). The gravity storage represents the quantity of water above field capacity that can be readily drained to recharge groundwater reservoirs and move laterally as slow moving interflow. The preferential flow store is used to model fast flowing interflow if there is a need to model macropores, preferential flow pathways, root channels or soil piping.

Lateral subsurface movement is conceptualized as a nonlinear Manabe (1969) type reservoir, allowing for a 3-D movement of variably saturated flow. The Hortonian overland flow runoff generation discussed above is added to saturation excess overland flow (i.e. when infiltration is in excess of the soil zone storage capacity). The routing of overland flow and lateral flow within the soil zone reservoir are carried out by a set of predefined flow pathways that reflect surficial topography. These pathways are termed cascading flow planes and allow for runoff and subsurface flow generated at an upslope cell to become an input to adjacent downslope cells (Figure 17.1 below). When applying the cascade flow planes over a high resolution topographical mesh, water is allowed to run downhill and interact with adjacent cells on its way to drainage features (e.g., streams and wetlands). This results in a greater potential for catchment moisture to be present in topographic lows (such as valleys, surficial depressions or road-side ditches), consistent with observation.

Channel routing in GSFLOW is governed by a 1-D kinematic wave approximation. Stream channel valleys can be represented by an eight point 
cross section in order to accommodate overbank flow processes. Lakes and reservoirs can have multiple inputs and outputs. Output control structures can have scheduled operational rule curves. Leakage between rivers and lakes is dependent on the hydraulic conductivity and head difference across the river or lake bed and is calculated on a cell by cell basis. Simulated total streamflow can be subdivided into multiple components: groundwater discharge (i.e. baseflow), interflow, and overland flow.

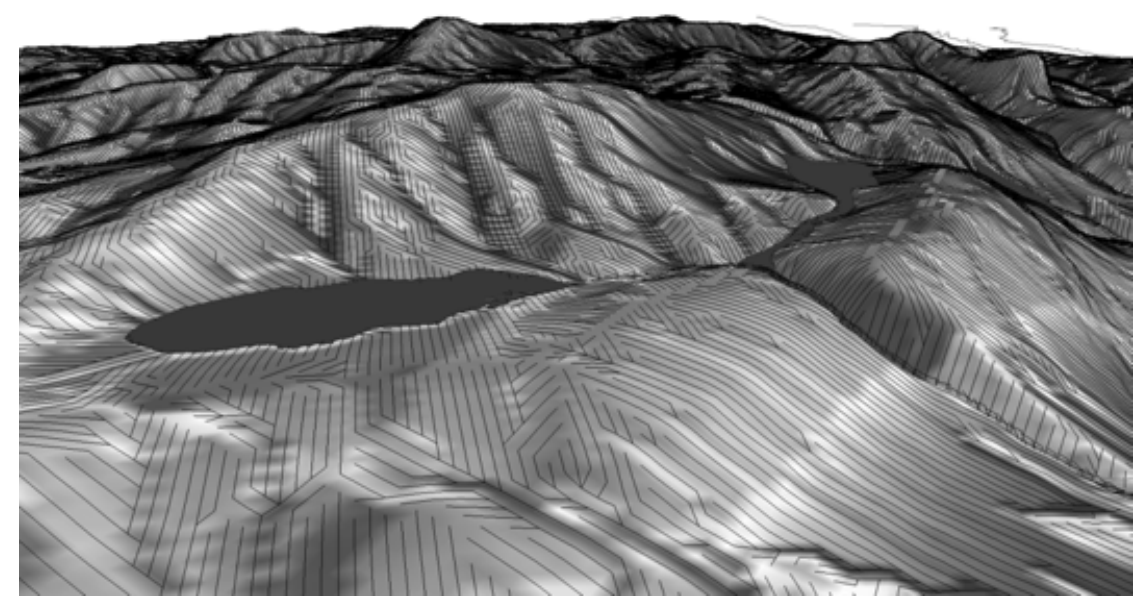

Figure 17.1 The accumulation of lateral water movement entering a wetland complex is directed by the cascading flow paths (thin black lines); darker shades indicate areas of greatest flow accumulation (vertical exaggeration is $10: 1$, grid resolution is $10 \mathrm{~m}$ ).

\subsubsection{Hydrogeology: Unsaturated and Saturated Groundwater Zone}

Water movement from the soil layer through the unsaturated zone to the water table is simulated using a 1-D kinematic wave approximation to the Richards equation that assumes diffusive gradients are negligible. With considerations for evapotranspiration losses from the unsaturated zone, the 1-D Richards approximation is governed by:

$$
\frac{\partial \theta}{\partial t}+\frac{\partial K(\theta)}{\partial z}+i=0
$$

where:

$$
\begin{gathered}
\theta=\text { the volumetric water content (i.e. volume of water per } \\
\text { volume of rock), }
\end{gathered}
$$


$z=$ length in the vertical direction,

$K(\theta)=$ the unsaturated vertical hydraulic conductivity as a

function of water content, which is estimated using the

function of Brooks and Corey (1966),

$i=$ the evapotranspiration rate beneath the soil zone base per

unit depth, and

$t=$ time.

The 1-D Richards approximation is solved first by using a method of characteristics approach whereby $\theta$ is taken partially in terms of $t$ and $z$, resulting in the above equation being separated into three components: velocity of a wave that represent wetting and drying in the unsaturated zone; the change in water content of the wave with time; and the change in water content with depth behind the wave during the drying phase (Niswonger et al., 2006).

Groundwater flow through the saturated zone is governed by Darcy's Law, which states that flow is proportional to the hydraulic gradient and to the hydraulic conductivity of the aquifer material and is given by:

$$
q=K \frac{d h}{d x}
$$

where:

$q=$ the specific discharge or rate of flow per unit area,

$K=$ the saturated hydraulic conductivity, and,

$d h / d x=$ the hydraulic gradient (change in hydraulic head per unit length).

Groundwater flow is also governed by the Law of Conservation of Mass which states that all inflows to a cell must be balanced by outflows or by a change in aquifer storage. When the mass balance equation is combined with Darcy's Law, it yields the governing equation for 3-D groundwater flow:

$$
\frac{\partial}{\partial x}\left(K_{x x} \frac{\partial h}{\partial x}\right)+\frac{\partial}{\partial y}\left(K_{y y} \frac{\partial h}{\partial y}\right)+\frac{\partial}{\partial z}\left(K_{z z} \frac{\partial h}{\partial z}\right)=S_{0} \frac{\partial h}{\partial t}
$$

where:

$K_{x x}, K_{y y}, K_{z z}=$ the hydraulic conductivity in the $x-, y-$ and $z-$ direction, respectively,

$h=$ the hydraulic head, and

$S_{0}=$ specific storage.

Hydraulic conductivity is a measure of how easily water can pass through the pores in the geologic unit. Specific storage is a measure of how much water is released per unit decline in aquifer head per unit volume of 
aquifer. Water is released from storage when the head decreases due to the expansion of the water and compression of the pore structure by the increase in intergranular stress. This increases as the water pressure decreases because total stress due to the weight of the overburden remains constant.

The differential equations listed above form the basis of the groundwater portion of GSFLOW. The equation is solved to determine aquifer heads and 3-D fluxes in all cells in all model layers within the active model area. Information in the form of aquifer properties, recharge and discharge rates and conditions along the study area boundaries, is provided as input to the model to make the solution unique to the study area. Numerical methods are needed to solve the equation because study area boundaries are irregular and aquifer and aquitard properties, aquifer geometry (stratigraphy), and rates of recharge and discharge tend to vary spatially.

\subsubsection{LID Representation in GSFLOW}

GSFLOW provides the ability to simulate a number of processes at a subcell resolution. A portion of each cell can be specified as impervious to represent paved areas or buildings. On the impervious areas, where no soil zone infiltration can occur, net precipitation must first satisfy depression storage while the excess is considered direct runoff. The pervious areas simulate a soil zone, surface depression storage, and interception storage dependent on canopy coverage and vegetation type, which control transpiration rates. The pervious areas can also accept a proportion of impervious runoff.

The authors have modified GSFLOW at the sub-cell process level to represent a number of LID designs. LID strategies that include some form of runoff detention can be conceptualized as Manabe (1969) type reservoir models (Figure 17.2). Based on storage depth and spatial extent, the area weighted linear storage capacity $\left(S_{\max }\right)$ can be determined. The current reservoir storage at time $t(S(t))$ is accounted for in GSFLOW and can be depleted through three mechanisms: evaporative loss ( $E$, generally set to the potential rate of evapotranspiration PET, but which can be user defined); reservoir drainage ( $D$, a user defined drainage rate that either represents water use for irrigation or an infiltration rate set to the local vertical hydraulic conductivity, $K$ ); and excess runoff $(Q)$ that occurs when the storage exceed the reservoir's maximum capacity, where $S(t)>S_{\max }$, and represents a simple overflow mechanism. From this basic conceptualization, many LID strategies can be simulated, such as green roofs $(E>0, Q>0, D=0)$; bioswales $(E>0, Q>0, D=K)$; rain barrels $(E=0, Q>0, D>0)$; underground rain harvesters $(E=0, Q>0, D=0)$; infiltration galleries $(E=0, Q>0, D=K)$; retention ponds $(E>0, Q=0, D>0)$; and detention ponds $(E>0, Q>0, D>0)$. 


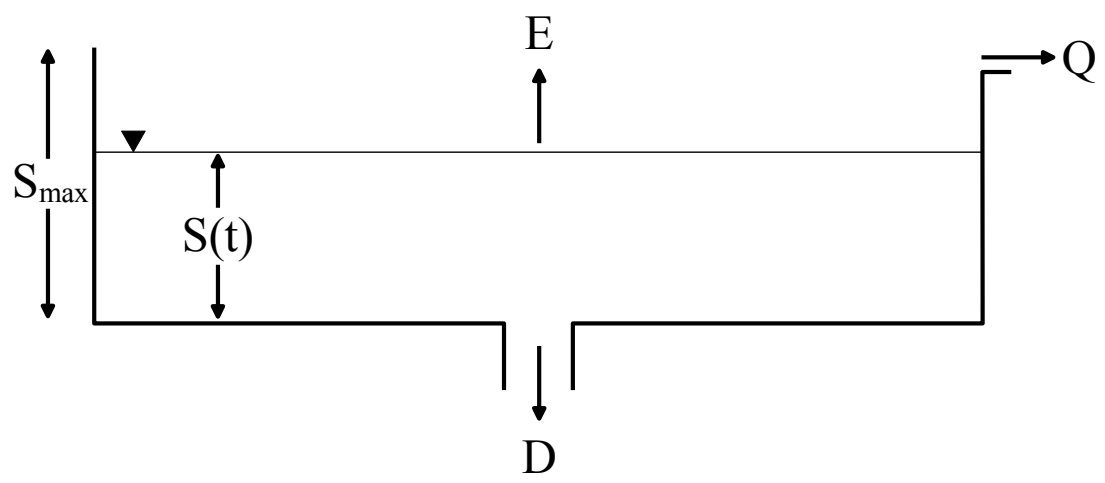

Figure 17.2 A simple Manabe-type reservoir used to model LID functionality is applied on a grid cell-by-cell basis.

Alternative LID designs can be represented in the existing GSLFOW pervious-impervious model structure. Pervious (porous) paving can be modeled by reducing the sub-cell effective impermeability, and downspout disconnects (i.e. roof to lawn) can be simulated by routing a portion of the runoff generated over the impervious area to the pervious area within every grid cell.

With these modifications and a high distributed resolution GSFLOW is able to predict the local and cumulative regional impacts and benefits of a number of different LID design scenarios. Brief examples are provided below.

\subsection{Integrated LID Assessment: A Case Study}

To demonstrate the integrated assessment of a variety of LID designs, a sample model application from the Greater Toronto region of Ontario, Canada is presented.

Much of the urban development in the Toronto region is located on a sloping till plain between the Oak Ridges moraine, to the north, and Lake Ontario to the south. The moraine consists of a $160 \mathrm{~km}$ long east-west trending ridge of partially confined sand and gravel sediments that are underlain by aquitard and aquifer units (Figure 17.3). The moraine is recognized as an important groundwater recharge area and the underlying aquifer units provide drinking water to hundreds of thousands residents. The surficial materials on the south flank of the moraine are mostly lower permeability tills; however, local deposits of glaciolacustrine beach sands are also present. The depth to water table and depth to groundwater recharge rates are variable on the south slope. The moraine also constitutes the headwaters of most of the streams and cold water fisheries in the area. 


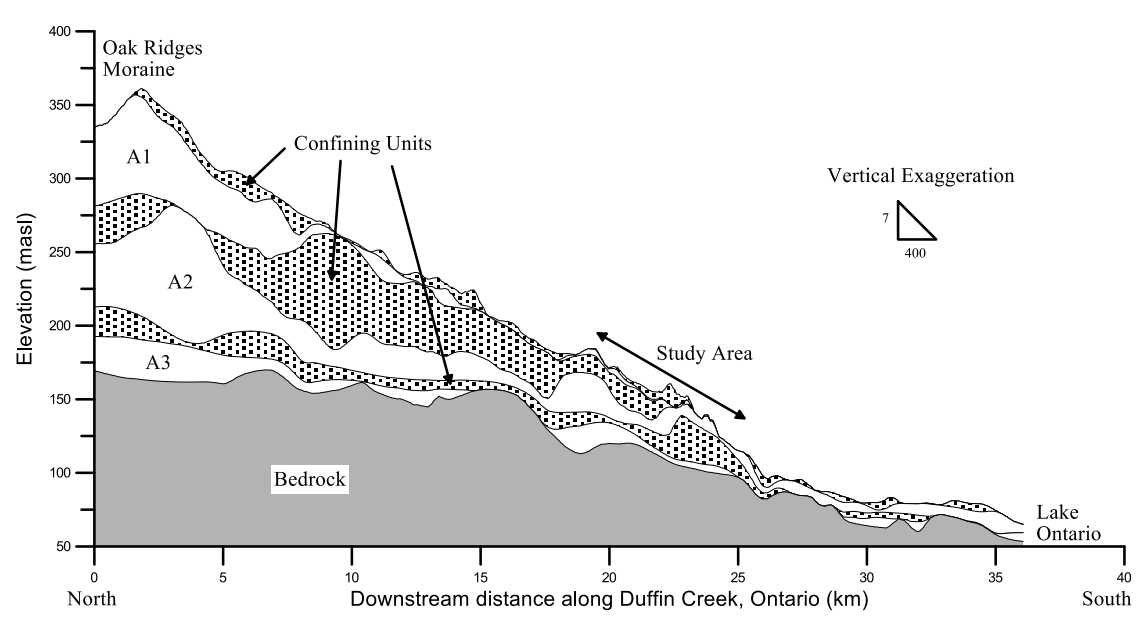

Figure 17.3 Geological cross section of the Oak Ridges moraine (south slope) showing the complex interaction of three major aquifers (labeled A1-A3) that all contribute baseflow discharge at specific reaches along Duffins Creek.

In order to protect the significant groundwater recharge areas on the crest of the moraine, a number of proposed land developments have been consolidated into a new community for 70000 residents on the southern flank of the moraine (see Study Area in Figure 17.3). This proposed new community is dissected by a number of existing streams, ponds and wetlands that must be preserved and protected from the effects of urban development. LID strategies were proposed to both minimize ecological impacts and to mitigate peak flows and storm water pond requirements. On a larger scale, the eastern and western extents of the proposed development are bounded by relatively deeply incised streams and riparian wetlands that support cold water fish spawning habitat. The cumulative impact of development on these reaches, as well as reductions in groundwater levels, was of regulatory concern. Within the development area the variable nature of the soil and subsurface conditions and the local configuration of the ponds and wetlands, together with the variety of planned development (e.g. residential vs employment areas), suggested that LID strategies needed to be carefully selected and locally optimized.

An existing groundwater model of the Oak Ridges moraine was developed using the USGS MODFLOW code (Kassenaar and Wexler, 2006). Storm water modeling in the area had previously been completed using the Visual OTTHYMO model. The following is a description of how the MODFLOW model was refined and upgraded to GSFLOW in order address LID selection, ecological impacts on wetlands and streams, and groundwater 
impacts due to changes in recharge, and how the GSFLOW results were used by the stormwater modeling team.

\subsubsection{Model Development and Baseline Conditions}

The existing MODFLOW model was locally refined and updated to reflect onsite drilling and field investigations. Particular attention was given to refining the shallow layer aquifer geometry and ensuring consistency between new surficial geologic mapping and the subsurface model layers. The steady state groundwater model was recalibrated to reflect local aquifer testing results.

Daily precipitation, minimum and maximum temperatures, and solar radiation were collected from multiple Environment Canada Atmospheric Environment Service gauges near the study site. Spatial interpolation among the sites was performed using an inverse distance squared weighting scheme.

The conversion to GSFLOW also included the development of the PRMS hydrology model inputs. A refined $10 \mathrm{~m}$ resolution soil and hydrology process grid was created to simulate the infiltration processes and detailed land use change. The updated groundwater and surface water components of GSFLOW were then used to predict baseline infiltration and groundwater recharge rates, groundwater levels in each aquifer, and baseline groundwater discharge to the streams and wetlands.

Distributed land use types were then altered to reflect the planned development (Figure 17.4a). Much of the planned development is concentrated in areas currently used for agriculture so natural features (wetlands and ponds) were already preserved, but not necessarily functionally protected.

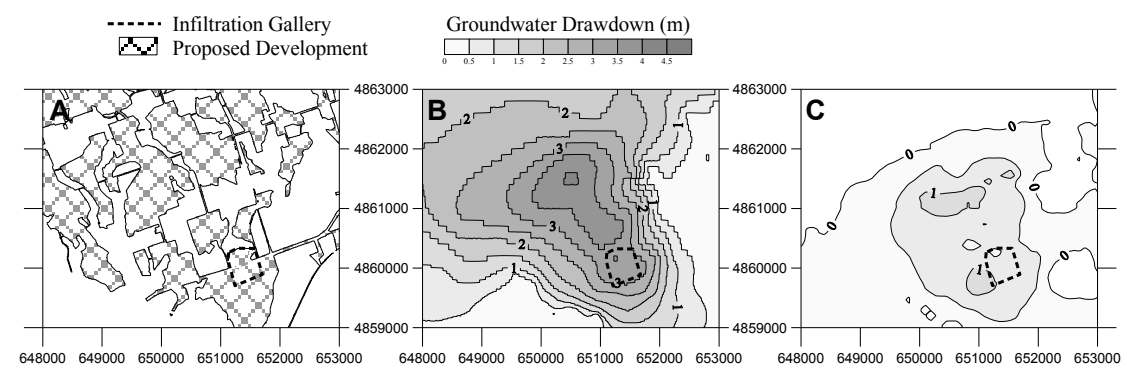

Figure 17.4 Improvement in groundwater drawdown from the placement of an infiltration gallery. (a) Proposed land development in areas that are currently used for agricultural purposes (areas in white generally consist of natural areas); (b) Groundwater drawdown caused by the development without mitigation; (c) Improvement of potential impacts by the application of LID strategies. Hatched area sourrounds the location of the proposed infiltration gallery. 
The GSFLOW model was then run under these development conditions and the results were compared to baseline conditions. In Figure 17.4b it is evident that development will have a significant impact on the groundwater system, causing drawdowns $>4.5 \mathrm{~m}$. Under these development conditions, where LID measures were not applied, a reduction in groundwater recharge was created by the increased imperviousness and the routing of storm runoff to SWMFs and nearby stream reaches. This development scenario put the aquifer system under stress as indicated by the drawdowns, which can be deleterious as the groundwater system is intimately connected to wetlands and streams. These results suggest a direct link between urbanization and ecological degradation.

\subsubsection{LID Example 1: Infiltration Enhancement}

In order to counteract these impacts, the modeling team experimented with LID strategies specific to infiltration enhancement. GSFLOW was used to simulate an infiltration gallery placed underneath a community area. Runoff from adjacent upslope areas was routed to the infiltration gallery, and excess water $(Q)$ was routed to SWMFs and streams. The infiltration gallery was assumed to be covered, and therefore evaporative losses $E=0$. The infiltration capacity of the gallery was expected to be the rate of vertical hydraulic conductivity $(D=K)$ of the underlying geologic materials.

Placing the infiltration gallery was challenging because in order to optimize its functionality it had to be placed in areas of relatively high conductivities such that the reservoir can drain at an acceptable rate. In addition, the depth to water table had to be well below the infiltration gallery so that the unsaturated zone had a capacity to accept large volumes of infiltration. In this case the modeling team restricted the placement of the gallery to areas where the depth to the water table was $>2 \mathrm{~m}$. A third placement restriction was that the gallery had to be placed such that it could be gravity fed from its contributing sources. Based on these restrictions, only one feasible location was found, and is outlined in Figure 17.4 above. The resulting infiltration gallery covered roughly $0.3 \mathrm{~km}^{2}$ and had an approximate capacity of $300000 \mathrm{~m}^{3}$ and was situated over an area characterized as being composed of glacio-fluvial and glacio-lacustrine deposits and a stoney/sandy/silt till. The net infiltration capacity of this area is roughly $3.3 \mathrm{~m} / \mathrm{y}$, assuming an unlimited supply of water.

The resulting reduction in groundwater drawdown was significant, with the infiltration gallery reducing the drawdown to approximately $1 \mathrm{~m}$, down from $4.5 \mathrm{~m}$ without the LID mitigation efforts (Figure 17.4c). Sustaining the existing groundwater levels also helped to preserve groundwater discharge to streams and wetlands, helping to preserve ecological features and functions. 


\subsubsection{LID Example 2: Distributed LID Planning}

Example 2 builds on example 1, but in this case, rather than determining the ideal location for a specific LID strategy, a number of LID scenarios related to the placement, functionality and form of varying LID methods were tested for their effectiveness in reducing generated runoff and increasing overall groundwater recharge. Using a detailed distribution of land use types, multiple LID scenarios were applied to fit developer needs and land use function by: (i) increasing evaporative loss and reducing runoff volumes through mechanisms such as green roofs, bioswales, increased soil depth, and increased vegetation density; (ii) increasing groundwater recharge through permeable/pervious/ porous surfaces and by capturing runoff and routing it to infiltration galleries constructed under impervious surfaces; and (iii) combining (i) and (ii) in the form of leaky detention ponds and roof runoff captured and routed though downspout disconnects to pervious areas.

The final LID design amounted to $2.5 \mathrm{~mm}$ capture with $90 \%$ of excess runoff being routed to bioswales in employment lands; roof-to-lawn routing of impervious runoff (amount dependent on roof coverage as a proportion of modeled cell) in residential, recreational and school areas; the infiltration gallery discussed above; and road side ditches along rural cross sections as opposed to serviced roadways.

From the results of the GSFLOW scenarios, the runoff generated within the catchment areas contributing to planned SWMFs were tabulated and provided to the storm water management modeling team. The team simulated the SWMFs and channel hydraulics using Visual OTTHYMO. Transferring results from GSFLOW to Visual OTTHYMO was accomplished by adjusting sub-catchment runoff coefficients in Visual OTTHYMO until runoff entering the SWMFs effectively matched the runoff predicted by GSFLOW. This collaboration that represents a loosely coupled modeling approach proved to be quite successful. The coupling of the two models does have its limitations: groundwater influences such as rejected recharge and discharge to streams are neglected; runoff coefficient adjustment is assumed to be an adequate representation of the hydrological change simulated by GSFLOW given the range of event magnitude of during the simulation period; and runoff from the contributing areas were assumed to arrive in the OTTHYMO as an instantaneous point source.

In summary, when compared with development without any impact mitigation, the simulation of cumulative LID measures helped to reduce overall groundwater drawdowns by $86 \%$, regained groundwater discharge to streams by $42 \%$, and reduced increased runoff generation by $80 \%$. GSFLOW was able to demonstrate real improvements to the hydrological system (other 
than runoff generation) from the application of LID strategies. The modeling team experimented with many LID scenarios, where subbasin-scale predictions of runoff where iteratively reintegrated into the storm water-erosion model analysis and design. This iterative approach helped to ensure that the right LID option was used where it could be most effective at mitigating impact to specific site-scale features.

There was additional concern with respect to the impact the land development would have on existing feature based water balances, specifically with respect to wetlands. Since GSFLOW models both groundwater discharge and overland flow contributions to these features, a detailed water balance of these features was undertaken to verify that the relative contributions from groundwater and surface water sources were not altered significantly when compared with baseline conditions. An example showing surficial runoff pathways directed to a wetland complex is shown in Figure 17.1 above, demonstrating the level of detail provided by the distributed model.

\subsection{Discussion}

The main objective of this chapter is to introduce the application of distributed modeling in order to assess the applicability low impact development (LID) strategies. We introduced GSFLOW, the new fully coupled, fully distributed groundwater and surface water model developed by USGS. The authors have added a Manabe-type reservoir into the GSFLOW sub-cell process model in order to simulate the functionality of many LID technologies currently available. These technologies include, but are not limited to: green roofs, rain barrels, downspout disconnections, pervious paving, bioswales, lined detention ponds, and infiltration enhancement facilities. In particular, we demonstrated how a covered infiltration gallery can be used to mitigate reduced groundwater recharge caused by development, and the challenges associated with the placement of such facilities. We also demonstrated how GSFLOW can be loosely coupled with a storm water management model such as SWMM to provide a holistic approach of urban hydrology impact assessment, and we discussed future possibilities of fully integrating SWMM with GSFLOW.

In summary, the GSFLOW analysis complements storm water modeling and thus provides for a collaborative means of LID analysis. This approach provides SWMM users with the necessary information to assess distributed LID effectiveness from multiple design scenarios. Our experience has demonstrated that scenario comparison is complex, and that site specific and integrated LID design analysis requires a distributed modeling approach. To achieve the benefits with respect to storm water management and preserving 
eco-hydrological systems, this important new water management approach must be taken.

\subsection{Conclusion and Future Applications}

In the examples discussed in the chapter we illustrated how GSFLOW, a distributed continuous groundwater and surface water model, can be coupled with common storm water management models such as SWMM. In the first example, we showed how LID strategies that involve some form of enhanced infiltration require the consideration of surficial geology and depth to water table, and hence required a distributed modeling approach. In the second scenario we showed how results from the distributed modeling of LID strategies (under different development scenarios) helped mitigate impacts to many ecological features, and provided point source runoff estimates for input into a storm water management model in order to assess LID effectiveness in improving water quality and reducing erosion hazards associated with peak flows. Since distributed LID modeling is in its infancy, we wish to highlight potential future applications for the use of distributed modeling coupled with storm water management models.

GSFLOW's cascade flow routine can explicitly determine overland flow routing pathways; therefore, at any point within the model's spatial domain, there is the ability to determine both groundwater heads and the accumulated overland flow contribution. As described earlier, this allows for the ability to quantify changes to feature based water balances by assessing relative contributions of surface water and groundwater entering wetlands and riparian areas; yet this detail can also be used to investigate infrastructure inflow and infiltration issues on a seasonal and continuous basis. The distributed nature of GSFLOW allows for the comparison of various sewer plans in order to mitigate influences from the groundwater system. GSFLOW can be adapted to work with any existing SWMM model; the only requirement is the locations of the links and nodes.

As GSFLOW can provide potential runoff contributions at any point in space, the model can be used to help determine the applicability, sizing, and placement of any LID strategy that is used to attenuate storm runoff events. Because GSFLOW runs continuous simulations, the robustness of LID can be tested on a seasonal basis.

Many LID designs can degrade over time and their original function can be impeded if they are not actively maintained. For example, the designed infiltration rate of pervious paving can be severely hampered by the deposition of sediment entrained in overland flow, and there is active research on 
methods to remediate this issue. As the distributed hydrology is modeled in a continuous manner, temporal LID degradation factors can be applied along with maintenance schedules in order to effectively capture LID effectiveness throughout its designed lifetime.

To address ecological concerns, GSFLOW can be applied to assess wetland hydroperiod (i.e. the seasonal fluctuations in wetland levels, storage and extent), how these natural fluctuations are impacted through development, and how these impacts can be mitigated through the use of LID strategies. Water particles that discharge into these features can be tracked back to their point of origin in order to protect ecologically significant groundwater recharge areas. The same goes for addressing impacts on cold water fishery reaches in neighbouring water courses.

Finally, because both GSFLOW and SWMM are open source, there is the potential to fully couple the models in order to allow for groundwater feedback mechanisms to affect inflow and infiltration processes on a continual and seasonal basis.

\section{References}

Brooks, R.H. and A.T. Corey, 1966. Properties of porous media affecting fluid flow: Journal of Irrigation and Drainage, v. 101, p. 85-92.

Credit Valley Conservation and Toronto and Region Conservation Authority, 2010. Low Impact Development Stormwater Management Planning and Design Guide Version 1.0 .

Dickinson, W.T. and H.Q. Whiteley, 1970. Watershed areas contributing to runoff: International Association of Hydrologic Sciences Publication 96, 1.12-11.28 p.

Freeze, R.A. and R.L. Harlan, 1969. Blueprint for a physically-based digitally-simulated hydrologic response model. Journal of Hydrology, 9: 237-258.

Green, W.H. and G.A. Ampt, 1911. Studies of Soil Physics, 1: The Flow of Air and Water Through Soils. Journal of Agricultural Science 4(1). pp.1-24.

Harbaugh, A.W., 2005. MODFLOW-2005, the U.S. Geological Survey modular groundwater model-the Ground-Water Flow Process: U.S. Geological Survey Techniques and Methods 6-A16, variously paginated.

Jensen, M.E., D.C.N. Rob and C.E. Franzoy, 1969. Scheduling irrigations using climatecrop-soil data, National Conference on Water Resources Engineering of the American Society of Civil Engineers: New Orleans, La. [Proceedings], p. 20.

Kassenaar, J.D.C. and E.J. Wexler, 2006. Groundwater modelling of the Oak Ridges Moraine area: YPDT-CAMC Technical Report \#01-06: Available at http://www.ypdtcamc.ca.

Leavesley, G.H., R.W. Litchty, B.M. Troutman and L.G. Saindon, 1983. PrecipitationRunoff Modeling System: User's Manual. Water Resources Investigations Report 83-4283. USGS. Denver Colorado. 
Manabe S., 1969. Climate and the ocean circulation 1. The atmospheric circulation and the hydrology of the Earth's surface. Monthly Weather Review 97(11). pp. 739-774.

Markstrom, S.L., R.G. Niswonger, R.S. Regan, D.E. Prudic and P.M. Barlow, 2008. GSFLOW: Coupled ground-water and surface-water flow model based on the integration of the Precipitation-Runoff Modeling System (PRMS) and the Modular Ground-Water Flow Model (MODFLOW-2005): U.S. Geological Survey Techniques and Methods 6-D1, $240 \mathrm{p}$.

Niswonger, R.G., D.E. Prudic and R.S. Regan, 2006, Documentation of the UnsaturatedZone Flow (UZF1) Package for modeling unsaturated flow between the land surface and the water table with MODFLOW-2005: U.S. Geological Survey Techniques and Methods 6-A19, $74 \mathrm{p}$.

United States Department of Agriculture: Soil Conservation Service, 1985. National Engineering Handbook, Section 4 - Hydrology: USDA-SCS, Washington, D.C. 
